\title{
Systemic lupus erythematosus and Raynaud's phenomenon*
}

\author{
Flavia Emilie Heimovski ${ }^{1}$ \\ Thelma Larocca Skare ${ }^{1}$
}

\author{
Juliana A. Simioni ${ }^{1}$
}

DOI: http:/ /dx.doi.org/10.1590/abd1806-4841.20153881

\begin{abstract}
BACKGROUnD: Patients with systemic lupus erythematosus seem to belong to different serological and clinical subgroups of the disease. Genetic background can cause the appearance of these subgroups.

Oвјестіvе: To determine whether Brazilian patients who have systemic lupus erythematosus and Raynaud's phenomenon differ from those who do not.

Methods: Retrospective analysis of 373 medical records of systemic lupus erythematosus patients studied for demographic, clinical and serological data. A comparative analysis was performed of individuals with and without RP.

RESUlTS: There was a positive association between Raynaud's phenomenon and age at diagnosis $(\mathrm{p}=0.02)$, presence of anti-Sm $(p=0.01)$ antibodies and anti-RNP $(p<0.0001)$. Furthermore, a negative association was found between Raynaud's phenomenon and hemolysis $(p=0.01)$, serositis $(p=0.01)$, glomerulonephritis $(p=0.0004)$ and $\operatorname{IgM}$ aCL ( $\mathrm{p}=0.004)$ antibodies.

CONCLUSION: Raynaud's phenomenon patients appear to belong to a systemic lupus erythematosus subset with a spectrum of clinical manifestations located in a more benign pole of the disease.
\end{abstract}

Keywords: Autoantibodies; Lupus erythematosus, systemic; Prognosis; Raynaud disease

\section{INTRODUCTION}

Raynaud's phenomenon (RP) is a nonspecific cutaneous lesion that appears in $18-46 \%$ of patients with systemic lupus erythematosus (SLE). ${ }^{1,2}$ It results from a vasospasm triggered by cold conditions or emotional stress that causes blanching, cyanosis, and reactive hyperemia of extremities. ${ }^{1} \mathrm{RP}$ is caused by vasoconstriction of the digital arteries, precapillary arterioles and cutaneous arteriovenous shunts; it has also been associated with digital ischemia and ulcers. ${ }^{3,4}$

SLE is an illness in which genetic background affects not only the disease's prevalence but also its phenotype. ${ }^{5}$ This allows for the appearance of clusters of autoantibodies and clinical findings that define the disease's subtypes. ${ }^{6.7}$ Knowledge of these clusters enables clinicians treating patients with given symptoms to watch out for those that are associated with it.

Some authors have linked the presence of RP to pulmonary hypertension; others have associated it with nervous system involvement. ${ }^{1,8}$ However, it remains unknown if the presence of RP in SLE patients suggests a different course of the disease in Brazilian patients.

This study analyzed the prevalence of RP in a sample of Brazilian SLE patients and whether this finding is associated with a peculiar clinical and serological profile.

Received on 26.07.2014

Approved by the Advisory Board and accepted for publication on 17.02.2015

Work performed at the Serviço de Reumatologia. Hospital Universitário Evangélico de Curitiba - Faculdade Evangélica do Paraná (Fepar) - Curitiba (PR), Brazil.

Financial Support: None.

Conflict of Interest: None.

1 Faculdade Evangélica do Paraná (Fepar) - Curitiba (PR), Brazil.

(C)2015 by Anais Brasileiros de Dermatologia 


\section{METHODS}

This retrospective study reviewed 373 charts from a single tertiary center, relating to SLE patients seen in the last 10 years, and approved by the local Research Ethics Committee. To be included patients must fulfill at least four of the 1997 revised American College of Rheumatology classification criteria for systemic lupus erythematosus. ${ }^{9}$ The study excluded patients diagnosed with the disease before the age of 16 and those with incomplete records. Data on demographic, clinical and serological profiles were obtained. The analyzed data refer to a non-probabilistic sample, with sequential and intentional selection, respecting the inclusion and exclusion criteria. The definition of clinical findings was that adopted in the ACR classification criteria. ${ }^{9}$ Patients were divided into two groups: those with and those without RP; they were then compared.

All data obtained were collected in frequency and contingency tables. The Kolmogorov-Sminorv test was used to study data distribution. Central tendency was expressed in median and interquartile range (IQR) as all numeric data were non-parametrical. Association studies were performed via Fisher's and chi-squared tests for nominal data, and through the Mann Whitney test for numerical data. Calculations were carried out with the help of the Graph Pad prism version 5.0 software. The significance adopted was of $5 \%$.

\section{RESULTS}

The studied sample had a $66.1 \%$ prevalence of auto-declared Caucasians and a $33.9 \%$ prevalence of auto-declared Afrodescendants, with a median disease duration of 48 months (range 1-384 months; IQR $=12-72$ ) and a median diagnosis age of 31 years (range $16-73$ years; $\mathrm{IQR}=23-40$ ). In this sample, $93.8 \%$ of patients were females, while $6.2 \%$ of patients were males.

The main clinical and serological findings are displayed in table 1 .

In this sample, the prevalence of Raynaud's phenomenon was of $183 / 373$ or $49.1 \%$.

Comparing lupus patients with and without RP, we found data in table 2 showing that RP was more common in older patients and in those with anti-RNP and anti-Sm. Glomerulonephritis, serositis, hemolytic anemia and anticardiolipin IgM antibodies were less common in this group.

\section{DISCUSSION}

Our results suggest that patients with RP experience disease onset at older ages and have less glomerulonephritis, which is one of the most serious manifestations of SLE. ${ }^{10}$ Approximately 10 to $30 \%$ of patients with the proliferative form progress to end- stage renal disease, needing dialysis or kidney transplants. ${ }^{10}$ In this context, the presence of RP would suggest a less severe disease. A study in 79 Serbian patients failed to demonstrate any link between RP and glomerulonephritis, while another with a larger number of American patients $(n=1.357)$ confirmed the negative association we found. ${ }^{1,4}$

It is consistently observed that RF is more common in people who experience disease onset at more advanced ages and in whom the lupus is considered less severe. ${ }^{4}$

This finding is highly important for clinics that monitor patients because it allows inferences to be made about the disease's prognosis, by drawing on simple clinical data obtained via anamnesis, such as the presence of RF.

Furthermore, the established association of RP with anti-RNP and anti-Sm autoantibodies has been noted by other researchers. ${ }^{7}$ Anti-RNP and anti-Sm antibodies are directed against spliceosome proteins and provoke the appearance of an ANA with a speckled pattern. ${ }^{11,12}$ Spliceosome is an intracellular structure that removes the intronic sequences of the pre-messenger RNA and links protein coding sequences to form mature RNA. ${ }^{11}$ RNP presence is considered nec-

TABLE 1: Clinical and serological profile of 373 systemic lupus erythematosus patients

\begin{tabular}{lll}
\hline & $\mathrm{N}$ & $\%$ \\
\hline Discoid lesion & $48 / 355$ & $14 \%$ \\
Butterfly rash & $195 / 351$ & $55.5 \%$ \\
Photosensitivity & $263 / 367$ & $71.6 \%$ \\
Oral ulcers & $160 / 359$ & $44.6 \%$ \\
Arthritis & $222 / 371$ & $59.8 \%$ \\
Serositis & $47 / 218$ & $21.5 \%$ \\
Hemolysis & $29 / 364$ & $7.9 \%$ \\
Leukopenia & $98 / 359$ & $27.3 \%$ \\
Thrombocytopenia & $86 / 353$ & $24 \%$ \\
Glomerulonephritis & $163 / 367$ & $44.4 \%$ \\
Seizures & $38 / 365$ & $10.4 \%$ \\
Psycosis & $15 / 215$ & $6.9 \%$ \\
Anti-Ro & $128 / 345$ & $37.1 \%$ \\
Anti-La & $66 / 345$ & $19.1 \%$ \\
Anti-Sm & $81 / 340$ & $23.8 \%$ \\
Anti-dsDNA & $124 / 350$ & $35.8 \%$ \\
Anti- RNP & $83 / 266$ & $31.2 \%$ \\
Anticardiolipin IgG & $48 / 349$ & $13.7 \%$ \\
Anticardiolipin IgM & $37 / 346$ & $10.6 \%$ \\
Lupus anticoagulant & $39 / 281$ & $13.9 \%$ \\
Rheumatoid factor & $88 / 322$ & $27.3 \%$ \\
& & \\
& & \\
& &
\end{tabular}


essary for mixed connective tissue disease diagnosis, but it appears in almost all connective tissue diseases. ${ }^{13}$ Anti-Sm is one of the most specific autoantibodies in SLE and is detected in 5 to $30 \%$ of SLE patients. It is nearly always accompanied by anti-RNP antibodies. ${ }^{13,14,15}$ Interestingly, Tapanes et al. had already associated the Sm/RNP group with the less severe form or with the absence of SLE glomerulonephritis. ${ }^{16}$ In addition, Hoffman et al. ${ }^{17}$ reported that SLE patients with $\mathrm{Sm} / \mathrm{RNP}$ antibodies had a lower prevalence of urine cellular casts, while To et al. ${ }^{7}$ observed that patients in the Sm/RNP cluster had the lowest incidence of renal manifestations.

The true value of the anti-RNP antibody is uncertain as it has not yet been linked to the disease's pathophysiological process. Some authors have regarded it merely as a disease marker. ${ }^{13}$ Interestingly, Levy et al. ${ }^{18}$ described the case of a lupus patient in which the appearance of severe RP was associated with the emergence of high titer anti-RNP seroconver- sion, suggesting that these autoantibodies may play a role in the pathogenesis of peripheral ischemic attacks.

Other negative clinical associations identified here and associated with hemolytic anemia and serositis, were not confirmed by Pavlov-Dolijanovic et al.. ${ }^{1}$ This relationship may be peculiar to the local ethnic background.

Finally, anticardiolipin $(\mathrm{aCl})$ antibodies have been studied in this context, yielding conflicting results. ${ }^{19,20} \mathrm{RP}$ is caused by vasospasm of the small muscular arteries and arterioles of the digits, not by thrombosis. ${ }^{19}$ Nevertheless thrombotic events may complicate severe forms with sustained vasospasm; patients affected by recalcitrant disease may benefit from anticoagulant therapy. ${ }^{9}$ Vayssairat et al..$^{20}$ found a significantly higher prevalence of aCL IgG in patients with RP and connective tissue disorders than in healthy controls. However, it is necessary to highlight that the prevalence of either antiphospholipid antibodies or RP is significantly higher in patients with

TABLE 2: Association studies with Raynaud's phenomenon (RP) in 373 systemic lupus erythematosus patients

\begin{tabular}{|c|c|c|c|}
\hline & $\begin{array}{l}\text { RP positive } \\
N=183\end{array}$ & $\begin{array}{l}\text { RP negative } \\
\mathbf{N}=190\end{array}$ & \\
\hline Gender (male/female) & $11 / 172$ & $12 / 178$ & 0.90 \\
\hline Disease duration (months) & $\begin{array}{l}1 \text { to } 384 \\
\text { Median } 48(\mathrm{IQR}=12-72)\end{array}$ & $\begin{array}{l}12 \text { to } 372 \\
\text { Median } 36.0(\mathrm{IQR}=12-72)\end{array}$ & 0.49 \\
\hline Age at diagnosis (years) & $\begin{array}{l}16-73 \\
\text { Median } 33(\mathrm{IQR}=24-42)\end{array}$ & $\begin{array}{l}\text { 16-64 } \\
\text { Median } 29.5(\mathrm{IQR}=22-38)\end{array}$ & 0.02 \\
\hline Tobacco exposure & $60 / 160-37.5 \%$ & $60 / 173-34.6 \%$ & 0.59 \\
\hline Discoid lesion & $28 / 173-16.2 \%$ & $20 / 182-10.9 \%$ & 0.15 \\
\hline Butterfly rash & $99 / 173-57.2 \%$ & $96 / 178-53.6 \%$ & 0.53 \\
\hline Photosensitivity & $134 / 179-74.8 \%$ & $129 / 188-68.6 \%$ & 0.18 \\
\hline Oral ulcers & $80 / 174-45.9 \%$ & $80 / 185-43.2 \%$ & 0.60 \\
\hline Arthritis & $105 / 183-57.3 \%$ & $117 / 188-62.2 \%$ & 0.34 \\
\hline Serositis & $14 / 98-14.2 \%$ & $33 / 120-27.5 \%$ & 0.01 \\
\hline Hemolitic anemia & $8 / 176-4.5 \%$ & $21 / 188-11.1 \%$ & 0.01 \\
\hline Leukopenia & $51 / 176-28.9 \%$ & $47 / 183-25.7 \%$ & 0.48 \\
\hline Thrombocytopenia & $49 / 172-28.4 \%$ & $37 / 181-20.4 \%$ & 0.07 \\
\hline Glomerulonephritis & $65 / 183-35.5 \%$ & $102 / 190-53.6 \%$ & 0.0004 \\
\hline Seizures & $13 / 176-7.3 \%$ & $15 / 189-13.2 \%$ & 0.06 \\
\hline Psychosis & $8 / 98-8.1 \%$ & $7 / 117-5.9 \%$ & 0.53 \\
\hline Anti-Ro & $68 / 169-40.2 \%$ & $60 / 176-34.1 \%$ & 0.23 \\
\hline Anti-La & $37 / 169-21.8 \%$ & $29 / 176-16.4 \%$ & 0.20 \\
\hline Anti-Sm & $49 / 167-29.3 \%$ & $32 / 173-18.5 \%$ & 0.01 \\
\hline Anti-dsDNA & $59 / 168-35.1 \%$ & $65 / 182-35.7 \%$ & 0.90 \\
\hline Anti-RNP & $55 / 126-43.6 \%$ & $28 / 140-20 \%$ & $<0.0001$ \\
\hline Anticardiolpin IgG & $19 / 170-11.1 \%$ & $29 / 179-16.2 \%$ & 0.17 \\
\hline Anticardiolipin IgM & $10 / 170-5.8 \%$ & $27 / 176-15.3 \%$ & 0.004 \\
\hline Lupus anticoagulant & $17 / 135-12.6 \%$ & $22 / 146-15.1 \%$ & 0.54 \\
\hline Rheumatoid factor & 49/163-- 30.1\% & $39 / 159-24.5 \%$ & 0.26 \\
\hline
\end{tabular}


connective tissue disorders than in the normal population. In a case-control study, limited to only 35 patients without SLE but with clinical disorders such as thrombosis, repeated abortions and thrombocytopenia, a positive association was found between $\mathrm{RP}$ and aCls. ${ }^{21}$ In contrast, a study of 93 SLE patients failed to establish any associations with this group of antibodies. ${ }^{19}$ We detected that $\mathrm{aCl}$ IgM was less common in patients with RP; other antiphospholipid antibodies did not show any association. ACl IgM is an antiphospholipid antibody that is less inclined to causing thrombosis than $\mathrm{aCl}$ IgG. ${ }^{22}$

\section{CONCLUSION}

The present findings suggest that although RP is considered a non-specific cutaneous lesion, it does provide important information on associated symptoms and the autoantibody profile in SLE. Its presence allows the establishment of a disease subgroup in which patients experience disease onset at an older age, presenting with clinical peculiarities such as lower prevalence of glomerulonephritis, serositis and hemolytic anemia. These patients therefore have a better prognosis. Still, this subgroup of SLE patients with FR is serologically marked by the autoantibodies anti-RNP and anti-Sm.

Identifying the different patterns of SLE presentation is important from a prognostic point of view, as the recognition of a simple clinical finding such as FR allows the attending doctor to predict the disease's evolution.]

\section{REFERENCES}

1. Pavlov-Dolijanovic S, Damjanov NS, Vujasinovic Stupar NZ, Marcetic DR, SefikBukilica MN, Petrovic RR. Is there a difference in systemic lupus erythematosus with and without Raynaud's phenomenon? Rheumatol Int. 2013;33:859-65.

2. Block JA, Sequeira W. Raynaud's phenomenon. Lancet. 2001;357:2042-8.

3. Rosato E, Molinaro I, Pisarri S, Salsano F. Digital Ulcers as an initial manifestation of systemic lupus erythematosus. Intern Med. 2011;50:767-9.

4. Bhatt SP1, Handa R, Gulati GS, Sharma S, Pandey RM, Aggarwal P, et al. Peripheral vascular disease in systemic lupus erythematosus. Lupus. 2007;16:720-3.

5. Boackle SA. Advances in lupus genetics. Curr Opin Rheumatol. 2013;25:561-8.

6. Jurencák R, Fritzler M, Tyrrell P, Hiraki L, Benseler S, Silverman E. Autoantibodies in pediatric systemic lupus erythematosus: ethnic grouping, cluster analysis, and clinical correlations. J Rheumatol. 2009;36:416-21.

7. $\mathrm{To} \mathrm{CH}$, Petri M. Is antibody clustering predictive of clinical subsets and damage in systemic lupus erythematosus? Arthritis Rheum. 2005;52:4003-10.

8. Artim-Esen B, Çene E, Şahinkaya Y, Ertan S, Pehlivan Ö, Kamali S, et al. Cluster analysis of autoantibodies in 852 patients with systemic lupus erythematosus from a single center. J Rheumatol. 2014;41:1304-10.

9. Hochberg MC. Updating the American College of Rheumatology revised criteria for the classification of systemic lupus erythematosus. Arthritis Rheum. 1997:40:1725.

10. Ortega LM, Schultz DR, Lenz 0, Pardo V, Contreras GN. Review: Lupus nephritis: pathologic features, epidemiology and a guide to therapeutic decisions. Lupus. 2010;19:557-74.

11. Migliorini P, Baldini C, Rocchi V, Bombardieri S. Anti-Sm and anti-RNP antibodies Autoimmunity. 2005;38:47-54.

12. Dellavance A, Gabriel Jr A, B Nuccitelli, Taliberti BH, von Mullen CA, Bichara CDA, et al. Third Brazilian Consensus for autoantibodies in search of Hep-2 cells (ANA). Recommendations for standardization of the screening test of self antibodies in Hep-2 cells, quality control and clinical associations. Rev Bras Rheumatol. 2009; 49:89-109.

13. Migliorini P, Baldini C, Rocchi V, Bombardieri S. Anti-Sm and anti-RNP antibodies. Autoimmunity. 2005;38:47-54.

14. Jurencák R, Fritzler M, Tyrrell P, Hiraki L, Benseler S, Silverman E. Autoantibodies in pediatric systemic lupus erythematosus: ethnic grouping, cluster analysis, and clinical correlations. J Rheumatol. 2009;36:416-21.

15. Zieve GW, Khusial PR. The anti-Sm immune response in autoimmunity and cell biology. Autoimmun Rev. 2003;2:235-40.

16. Tápanes FJ, Vásquez M, Ramírez R, Matheus C, Rodríguez MA, Bianco N. Cluster analysis of antinuclear autoantibodies in the prognosis of SLE nephropathy: are anti-extractable nuclear antibodies protective? Lupus. 2000;9:437-44.
17. Hoffman IE, Peene I, Meheus L, Huizinga TW, Cebecauer L, Isenberg D, et al. Specific antinuclear antibodies are associated with clinical features in systemic lupus erythematosus. Ann Rheum Dis. 2004;63:1155-8.

18. Levy O, Maslakov I, Vosco S, Markov A, Amit-Vazina M, Tishler M. Critical peripheral ischemia precipitated by severe episode of Raynaud's phenomenon in a patient with aPL-positive systemic lupus erythematosus, upon high titer antiRNP seroconversion. Lupus. 2015;24:327-30.

19. Caccavo D, Del Porto F, Garzia P, Mitterhofer AP, Galluzzo S, Rigon A, et al. Raynaud's phenomenon and antiphospholipid antibodies in systemic lupus erythematosus: is there an association? Ann Rheum Dis. 2003;62:1003-5.

20. Vayssairat M, Abuaf N, Baudot N, Deschamps A, Gaitz JP. Abnormal IgG cardiolipin antibody titers in patients with Raynaud's phenomenon and/or related disorders: prevalence and clinical significance. J Am Acad Dermatol. 1998;38:555-8.

21. Naldi L, Locati F, Marchesi L, Cortelazzo S, Finazzi G, Galli M, et al. Cutaneous manifestations associated with antiphospholipid antibodies in patients with suspected primary antiphospholipid syndrome: a case-control study. J Am Acad Dermatol. 1998;38:555-8.

22. Sammaritano LR, Ng S, Sobel R, Lo SK, Simantov R, Furie R, et al Anticardiolipin IgG subclasses: association of IgG2 with arterial and/or venous thrombosis. Arthritis Rheum. 1997;40:1998-2006.

MAILING ADDRESS:
Thelma Larocca Skare
Alameda Augusto Stellfeld, 1908
Bigorrilho
80730-150 - Curitiba-PR
Brazil
E-mail: tskare@onda.com.br

MAILING ADDRESS:

Thelma Larocca Skare

Alameda Augusto Stellfeld, 1908

Bigorrilho

Brazil

How to cite this article: Heimovski FE, Simioni JA, Skare TL. Systemic lupus erythematosus and Raynaud's phenomenon. An Bras Dermatol. 2015;90(6):837-40. 